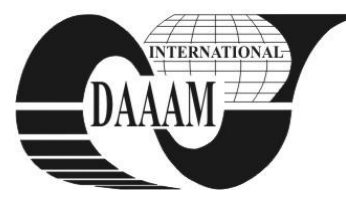

\title{
MATERIAL FLOW DESIGN AND SIMULATION OF PART PRODUCTION IN THE FREE MACHINES LAYOUT
}

\author{
KRAJCOVA, K[atarina]; PECHACEK, F[rantisek] \& VELISEK, K[arol]
}

\begin{abstract}
Material flow design, its simulation and selection of organizational form of machines layout is important part of production design. The further part of the production design is the selection of machines layout form, which depends on the material flow. It is included technological, subject, free, modular and cellular layout. Free machines layout was selected for the shaft production, because it was not possible advance exactly to determine the material flow, organizational and running relations and following individual operations. The machines and conveyors utilization was possible to determine on the based of material flow simulation in Witness program. On the based statistics I recommend to realize the further research, which will consist in the change of machines layout, for example cellular.
\end{abstract}

Key words: material flow, design, simulation, machines layout, Witness program

\section{INTRODUCTION}

Due emphasis should be put in design of material flow and selection of organizational machines layout form at the production design. Several production system fails to incorrect material flow design and selection of machines layout form. Therefore it is necessary to highlight the importance of this phase production design.

The issue of appropriate machines layout and material flow design is currently the important part of production design in the each company. The machines is possible to lay out in several ways, which are referred as the organizational form of machine layout. It is included technological, subject, free, modular and cellular machines layout. The free layout was selected for the part production, which is characterized by random alignment of machines. The free layout is used in the cases, if it is not possible advance exactly to determine the material flow, following individual operations, organizational and running relations.

On the based of this layout is possible then to determine and simulate the material flow and determine the utilization of individual machines, conveyors and other auxiliary production elements.

\section{DESIGN OF MATERIAL FLOW AND ITS SIMULATION}

Material flow is possible to characterize as a movement of passive elements (material, raw materials, products), which is secured by active elements (transport, handling and storage systems). (Koštál et al., 2010) It means, that by the design of material flow it is possible to specify the individual active and passive elements of production system.

\subsection{Part specification}

Modeled part, which will be pass through the production system is rotating part - shaft (fig. 1) with the following parameters:

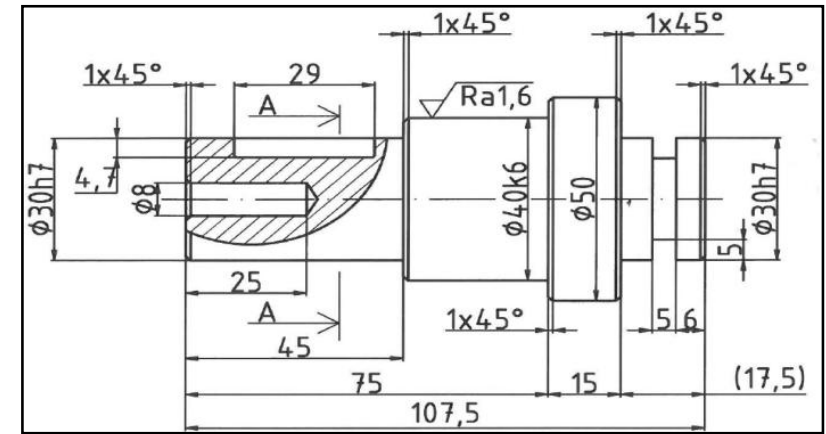

Fig. 1. 2D model of part - shaft

\subsection{Modeling and simulation of material flow}

The modeling and simulation is very important part of each production design. In most cases is dependent on the modeling and simulation the realization of production process. It means, that the modeling principle is to replace the examined system with modeling system, that it was found its efficiency and possible losses in the production. In the examined system is subsequently possible to edit the production conditions on the based simulation in a program. These conditions affect the properties of whole production system. (Horváth \& Mudriková, 2010) These parameters are corrected:

$>$ times of individual operations,

$>$ maximum number of parts in a buffer,

$>$ settings of machines,

$>$ the number of conveyors and other auxiliary transport devices. (Važan et al., 2008)

The program designed to modeling and simulation of material flow significantly facilitate the production design, which is very demanding and time-consuming part of production design. (Matúšová \& Javorová, 2010) The group shall be assigned the following programs:

1) Plant Simulation,

2) Quest

3) Simul 8,

4) Mantra $4 \mathrm{D}$,

5) Witness.

Witness is one of the worlds most successful simulation program, which is designed for simulation of production, utility and logistics processes. This program can be used in many areas, for example:

$>$ interactive creation of models and modular structure,

$>$ interactive experiments,

$>$ cooperation with $\mathrm{CAD}, \mathrm{CAM}$ applications and information systems,

$>$ creation of uniform optimization module,

$>$ 3D vizualization - module of virtual reality. (http://www.sjf.tuke.sk, 2006)

Witness program is world- renowned simulation program, therefore is used for material flow simulation of shaft production too. 
2.2.1 Simulation of shaft production in the Witness program

The task of this production system is the implementation of technological process in such a way, that the part created from semi-finished product with prescribed geometric and qualitative properties.

The semi-finished product is a rod, which passes through the production system in such a way, that the shaft with prescribed parameters was a product of production system.

$3 \mathrm{D}$ simulation of production system in the Witness program is on the figure 2 .

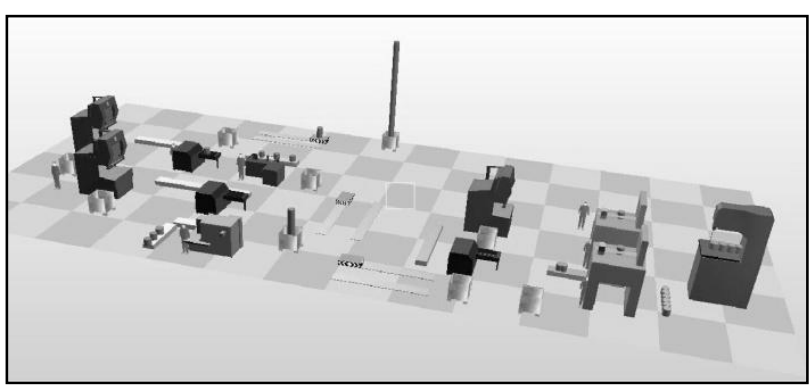

Fig. 2. 3D simulation of production system with free machines layout in the Witness program

The system consists from five machines tool, namely:

$>$ a saw for cutting of semi-finished product with the prescribed length,

$>$ two lathes with a operator,

$>$ a milling with operator,

$>$ grinding machine with operator.

The lathes, milling and grinding machine are assigned three devices acting the inspection of workpiece dimensions and three machines acting the parts repair, whose the dimensions do not correspond to the dimensions in the technical documentation. The material flow between the technological workplaces is carried by the vehicles, which are running on the created tracks and material flow within a single technological workplace by conveyor belts. A buffer for dimensionally correct parts and faulty parts is assigned to the appropriate machines.

\section{THE RECOVERY OF MATERIAL FLOW DESIGN AND A MACHINES LAYOUT}

Witness program was used to create of simulation model of production system, which produce the specified part. The function model of production system and its spatial distribution on the particular area was designed in a first phase. The second part of system design was devoted to adjustment the machines parameters (for example tool time, inputs and outputs from the machines). The rejects creation was necessary to adjust in the production. Further was starting the simulation, which was eight-hours workshift and the statistical data and a number of produced parts were observed.

The figure 3 shows the machines utilization in the free layout.

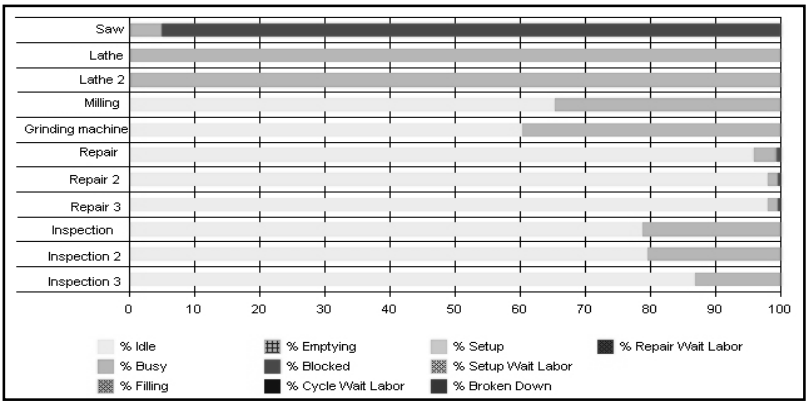

Fig. 3. The chart of machines utilization in the free layout
The chart shows, the saw is blocked at $95 \%$, because the saw produces the semi-finished products after the buffer filling. Divided semi-finished products remain in the saw and cause the blocking. Further the chart shows the operations quantity of individual machines and devices. The quantity of devices „Inspection3“ indicates the number of produced per shift shafts.

The figure 4 shows the conveyor utilization in the free layout.

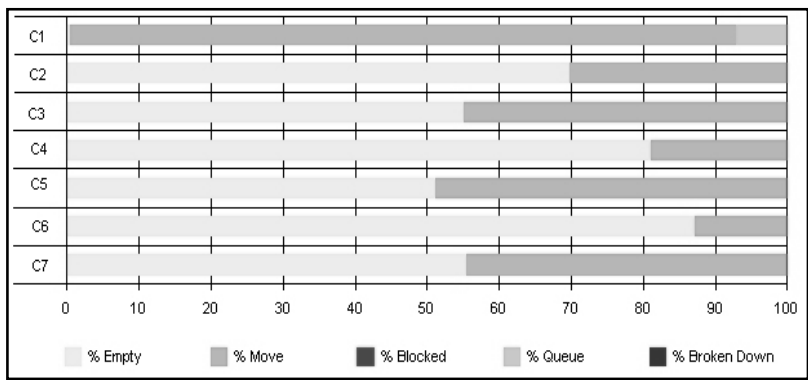

Fig. 4. Conveyors utilization in the free layout

\section{CONCLUSION}

The design of material flow and organizational layout form of machines and devices currently consider as the important part of each production design.

In the production system for shaft production with free machines layout was designed the material flow, which is possible to rejuvenate by the addition or reducing of several auxiliary elements of production.

I recommend to realize the further research, which is going to consist in the simulation of production system in the Witness program, but for other input conditions. This means, that other organizational layout form of machines is going to select, for example cellular. The cellular organizational layout form of machines is appropriate to group the machines with similar functional properties, for example the inspection and repair should unit into a single device, thereby the production costs should substantially reduce.

\section{ACKNOWLEDGEMENTS}

This paper was created thanks to the national grant VEGA 1/0206/09 - INTELLIGENT ASSEMBLY CELL.

\section{REFERENCES}

Horváth, Š.,\& Mudriková, A., Material flow simulation in production, In: MicroCAD 2010: Section P: Material Flow Systems. Logistical Information Technology, XXIV. International Scientific Conference, (2010), p. 83-87, ISBN 978-963-661-920-6

Koštál, P., Mudriková, A. \& Sobrino, D. R. D., Material flow in flexible production systems, In: Proceedings in Manufacturing Systems, Vol. 5, No. 4 (2010), p. 213-216, ISSN 2067-9238

Matúšová, M. \& Javorová, A., Material flow analysis of designed flexible manufacturing cell, In: Proceedings in Manufacturing Systems, Vol. 5, Special Number (2010), p. 285-290, ISSN 2067-9238

Važan, P., Schreiber, P. \& Križanová G., Simulation Optimization with the Witness Simulator, In: Ecumict 2008: Proceedings of the Third European Conference of the Use of Modern Information and Communication Technologies (2008), p. 461-469, ISBN 9-789-08082-553-6

*** (2006) http://www.sjf.tuke.sk - Simulation as an instrument to solve problems by means of Witness software, Transfer inovácií, Accessed on: 2011-06-05 